\title{
Continuous improvement in patient safety and quality in neurological surgery: the American Board of Neurological Surgery in the past, present, and future
}

\author{
Marjorie C. Wang, MD, MPH, ${ }^{1}$ Frederick A. Boop, MD, ${ }^{2}$ Douglas Kondziolka, MD, ${ }^{3}$ \\ Daniel K. Resnick, MD, MS, ${ }^{4}$ Steven N. Kalkanis, MD, ${ }^{5}$ Elizabeth Koehnen, MA, ${ }^{6}$ \\ Nathan R. Selden, MD, PhD, ${ }^{7}$ Carl B. Heilman, MD, ${ }^{8}$ Alex B. Valadka, MD, ${ }^{9}$ \\ Kevin M. Cockroft, MD, MSc, ${ }^{10}$ John A. Wilson, MD, ${ }^{11}$ Richard G. Ellenbogen, MD,12 \\ Anthony L. Asher, MD, ${ }^{13}$ Richard W. Byrne, MD, ${ }^{14}$ Paul J. Camarata, MD, ${ }^{15}$ Judy Huang, MD, ${ }^{16}$ \\ John J. Knightly, MD, ${ }^{17}$ Elad I. Levy, MD, MBA, ${ }^{18}$ Russell R. Lonser, MD, ${ }^{19}$ \\ E. Sander Connolly Jr., MD, ${ }^{20}$ Fredric B. Meyer, MD, ${ }^{21}$ and Linda M. Liau, MD, PhD, MBA ${ }^{22}$
}

1Department of Neurosurgery, Medical College of Wisconsin, Milwaukee, Wisconsin; ${ }^{2}$ Department of Neurosurgery, The University of Tennessee Health Science Center, Memphis, Tennessee; ${ }^{3}$ Department of Neurosurgery, New York University School of Medicine, New York, New York; ${ }^{2}$ Department of Neurosurgery, University of Wisconsin Medical School, Madison, Wisconsin; ${ }^{5}$ Department of Neurosurgery, Henry Ford Health System, Detroit, Michigan; ${ }^{6}$ American Board of Neurological Surgery, Rochester, Minnesota; ${ }^{7}$ Department of Neurological Surgery, Oregon Health \& Science University, Portland, Oregon; ${ }^{8}$ Department of Neurosurgery, Tufts Medical Center, Boston, Massachusetts; ${ }^{9}$ Department of Neurosurgery, Virginia Commonwealth University, Richmond, Virginia; ${ }^{10}$ Department of Neurosurgery, Penn State Hershey Medical Center, Hershey, Pennsylvania; ${ }^{11}$ Department of Neurosurgery, Wake Forest Baptist Health, Winston-Salem, North Carolina; ${ }^{12}$ Department of Neurological Surgery, University of Washington School of Medicine, Seattle, Washington; ${ }^{13}$ Neuroscience Institute, Carolinas Healthcare System and Carolina Neurosurgery \& Spine Associates, Charlotte, North Carolina; ${ }^{14}$ Department of Neurosurgery, Rush University Medical Center, Chicago, Illinois; ${ }^{15}$ Department of Neurosurgery, University of Kansas, Kansas City, Kansas; ${ }^{16}$ Department of Neurosurgery, Johns Hopkins University School of Medicine, Baltimore, Maryland; ${ }^{17}$ Atlantic Neurosurgical Specialists, Morristown, New Jersey; ${ }^{18}$ Department of Neurosurgery, University at Buffalo, New York; ${ }^{19}$ Department of Neurological Surgery, The Ohio State University Wexner Medical Center, Columbus, Ohio; ${ }^{20 D e p a r t m e n t ~ o f ~ N e u r o l o g i c a l ~ S u r g e r y, ~}$ Columbia University Medical Center, New York, New York; ${ }^{21}$ Department of Neurosurgery, Mayo Clinic, Rochester, Minnesota; and ${ }^{22}$ Department of Neurosurgery, David Geffen School of Medicine at UCLA, Los Angeles, California

The American Board of Neurological Surgery (ABNS) was incorporated in 1940 in recognition of the need for detailed training in and special qualifications for the practice of neurological surgery and for self-regulation of quality and safety in the field. The ABNS believes it is the duty of neurosurgeons to place a patient's welfare and rights above all other considerations and to provide care with compassion, respect for human dignity, honesty, and integrity. At its inception, the ABNS was the 13th member board of the American Board of Medical Specialties (ABMS), which itself was founded in 1933. Today, the ABNS is one of the 24 member boards of the ABMS.

To better serve public health and safety in a rapidly changing healthcare environment, the ABNS continues to evolve in order to elevate standards for the practice of neurological surgery. In connection with its activities, including initial certification, recognition of focused practice, and continuous certification, the ABNS actively seeks and incorporates input from the public and the physicians it serves. The ABNS board certification processes are designed to evaluate both real-life subspecialty neurosurgical practice and overall neurosurgical knowledge, since most neurosurgeons provide call coverage for hospitals and thus must be competent to care for the full spectrum of neurosurgery.

\footnotetext{
ABBREVIATIONS AANS = American Association of Neurological Surgeons; $A B M S=$ American Board of Medical Specialties; ABNS $=$ American Board of Neurological Surgery; $A C G M E=$ Accreditation Council for Graduate Medical Education; $A M A=$ American Medical Association; $C C=$ continuous certification; $C M E=$ continuing medical education; MOC = Maintenance of Certification; POST = Practice and Outcome of Surgical Therapies; SNS = Society of Neurological Surgeons. SUBMITTED June 2, 2020. ACCEPTED June 18, 2020.

INCLUDE WHEN CITING Published online October 16, 2020; DOI: 10.3171/2020.6.JNS202066.
} 
The purpose of this report is to describe the history, current state, and anticipated future direction of ABNS certification in the US.

https://thejns.org/doi/abs/10.3171/2020.6.JNS202066

KEYWORDS neurological surgery; specialty boards; public health; certification; humans; history

$\mathrm{T}$ HE American Board of Neurological Surgery (ABNS) was incorporated on July 27, 1940. The concept of an independent board was discussed for several years prior to 1940 , as neurosurgeons recognized the need for detailed training in and special qualifications for the practice of neurosurgery. Preceding events included publication of the Flexner report in $1910,{ }^{1}$ which raised concerns about the quality of medical education and medical schools and heightened awareness of wide variations in the quality of clinical care across the country. ${ }^{2}$ In 1912 , the Federation of State Medical Boards was formed. This group worked with the American Medical Association (AMA) to identify unethical physicians. In 1915, the National Board of Medical Examiners was founded to create examinations to better assess physician knowledge. Specialty boards began to form to help physicians self-regulate and to develop standards for education and quality of care. ${ }^{3}$ Two preexisting boards, the American Board of Psychiatry and Neurology (1934) and the American Board of Surgery (1937), were interested in certifying neurosurgeons. However, most neurological surgeons did not want these broader boards to certify neurosurgeons; rather, they thought that they, as neurosurgeons, would be best able to certify practitioners in their own specialty. ${ }^{4}$

On March 27, 1939, representatives from the Society of Neurological Surgeons (SNS) and the Harvey Cushing Society (now the American Association of Neurological Surgeons [AANS]) held an informal gathering to discuss this concept. Those in attendance were Drs. Alfred W. Adson, Paul C. Bucy, Winchell McK. Craig, Loyal Davis, Howard C. Naffziger, Eric Oldberg, Max M. Peet, and R. Glen Spurling. This founders group unanimously decided that a separate board should be formed for certification in neurological surgery. Dr. Naffziger drafted the initial articles of incorporation and served as the first chair. This group was later expanded to include representatives from the AMA's Section on Nervous and Mental Diseases and Section on Surgery, the American Neurological Association, and the American College of Surgeons.

Drs. Leo Davidoff, Temple Fay, and Paul Bucy designed the first certificate and seal of the board. The directors were not compensated for their time, but they did receive reimbursement for coach or train travel plus $\$ 10$ a day for hotel and food. The initial cost of ABNS certification was set at $\$ 50$ and then quickly increased to $\$ 75$. In today's dollars, this is approximately $\$ 1350$. Over time, various neurosurgical societies petitioned for the right to nominate ABNS directors, leading to the current nomination structure of the board of directors, discussed below. In 1940, the year of its formation, the ABNS also became the 13th member board of the American Board of Medical Specialties (ABMS).

The ABNS is dedicated to serving the public interest by promoting neurological surgery quality, safety, and appropriateness. The ABNS maintains and has evolved a system of national standards to promote quality health- care, which include, among other elements, guidelines for graduate and postgraduate medical education programs and a variety of physician assessment systems at every level of professional experience. Successful participation in prescribed training and evaluation processes ultimately leads to "certification" of physician specialists, a designation intended to assure society that individual practitioners have attained benchmark knowledge and skills and are committed to meeting shared standards of continuous professional learning and development throughout their careers. All elements of the ABNS certification process allow for essential insights into candidates' relative abilities to provide safe, evidence-based, and compassionate care. As of May 2020, 5642 neurosurgeons have active ABNS certificates (https://abns.org/).

\section{The Current ABNS Board of Directors}

Currently, the ABNS consists of 15 directors and officers selected from practicing neurosurgeons certified by the board. Directors are elected after nominations are received from the following societies: AANS (4), SNS (4), Congress of Neurological Surgeons (4), American Academy of Neurological Surgery (1), Neurosurgical Society of America (1), and The American Society of Pediatric Neurosurgeons (1). Directors and the executive director volunteer their time and service, without monetary compensation. Each director serves for a single 6-year term. Appointments are staggered so that two or three new directors are elected to the board each year. The selection of directors is merit based, which includes an objective assessment of their professional accomplishments, scholarship, contributions to the profession of neurological surgery in various capacities, and national/international reputation, as well as a demonstrated willingness to devote typically hundreds of volunteer hours each year during their tenure. In addition, directors are selected to maintain a board that is diverse with respect to demographics, subspecialty, director nonneurosurgical competencies (e.g., information technology, finance, educational assessment), practice type, and geography. Current and past directors, as well as other neurosurgeons who participate in the oral examination, are precluded for a period of time from participating in board review courses unless approved by the ABNS Executive Committee. All directors, regardless of when they were initially certified, are also expected to participate in continuous certification (CC) and to actively practice as neurosurgeons (Fig. 1). Approximately 220 neurosurgeons have served as directors since the ABNS was incorporated in 1940.

\section{Curriculum and Primary Examination Curriculum}

The ABNS works in conjunction with the Neurological Surgery Residency Review Committee of the Accredita- 
Wang et al.
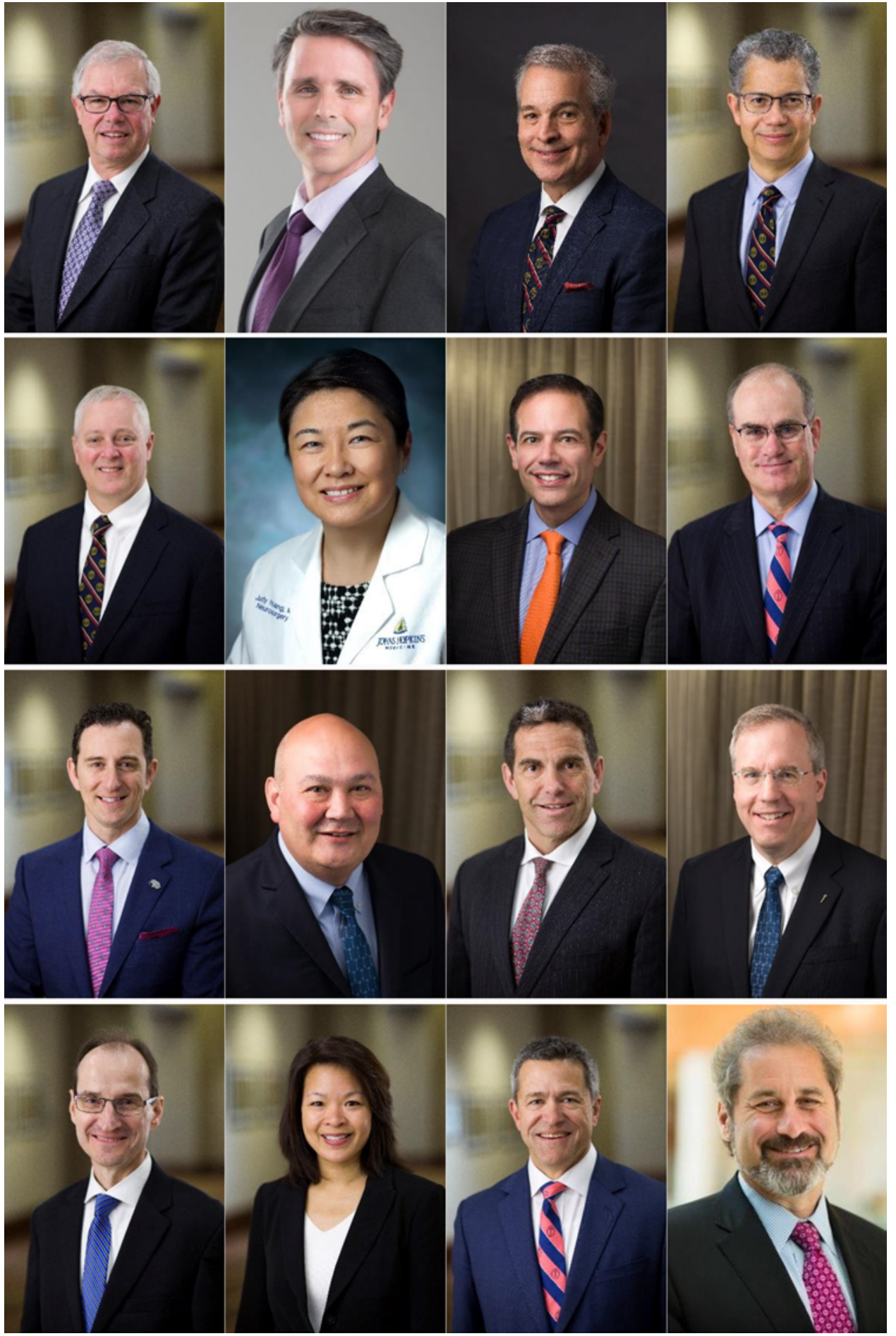

FIG. 1. ABNS Board of Directors (as of June 2020). Top row: Frederick A. Boop, MD; Richard W. Byrne, MD; Paul J. Camarata, MD; Kevin M. Cockroft, MD, MSc. Second row: Carl B. Heilman, MD; Judy Huang, MD; Steven N. Kalkanis, MD; John J. Knightly, MD. Third row: Elad I. Levy, MD, MBA; Russell R. Lonser, MD; Daniel K. Resnick, MD, MS; Nathan R. Selden, MD, PhD. Bottom row: Alex B. Valadka, MD; Marjorie C. Wang, MD, MPH; John A. Wilson, MD; Fredric B. Meyer, MD. Copyright Elizabeth Koehnen. Published with permission. Figure is available in color online only. 
TABLE 1. Information needed to apply for the ABNS oral examination

\begin{tabular}{l}
\hline Basic profile information \\
\hline Detailed training \& practice information \\
\hline Hospital privileges \\
\hline Hospital verification form for completed case log \\
Minor case log \\
\hline Curriculum vitae \\
\hline Business card \\
\hline Business Associate Agreement \\
\hline Minimum of 5 references: the original 5 requested professional areas \\
are directed by ABNS. Additional reference requests are generated \\
by candidate answers to parts of the application, such as fellow- \\
ships, outside rotations, more than one practice experience, etc.
\end{tabular}

tion Council for Graduate Medical Education (ACGME) and the SNS to design and direct the curriculum for all neurosurgery residents. These organizations work together to ensure that the individual requirements for $\mathrm{ABNS}$ certification are supported by and aligned with the training environment requirements for residency program accreditation of the ACGME and are supported by highquality curricula and well-prepared program leadership. Together, the requirements for training, residency case log minimums, and areas of study (i.e., neurocritical care, research, etc.) are defined and adjusted to reflect the needs of patients, the field, and US healthcare.

\section{Primary Examination/In-Training Examination/Written Examination}

The primary examination was first given in 1963 when the ABNS noticed a wide range of success in candidates sitting for the oral examination and sought to improve the knowledge base obtained during residency. The ABNS was the first certifying board to administer a written examination to trainees. ${ }^{4}$ Currently, the primary examination is a written one consisting of 375 single-best-answer multiple-choice questions evaluating fundamental knowledge of neurosurgery and related disciplines. This examination must be passed to complete residency and is one of the requirements for board certification.

The primary examination was traditionally designed in consultation with psychometricians to generate scores on a bell-shaped curve, whereby only a few candidates achieved a high percentage of correct answers, similar to entrance examinations used for selection purposes. Over the last several years, the ABNS has been transitioning the primary examination from an evaluative examination to a mastery examination, with the intent that all passing candidates show proficiency in the core knowledge base required for the practice of neurosurgery. A concerted effort has been made to increase the clinical relevance of examination questions and to exclude questions that require rote memorization of information that could be easily accessed (i.e., drug dosages, etc.). The psychometric performance of primary examination questions is evaluated across examinations, and the ABNS continues to work to eliminate questions that exhibit unusual or counterintuitive profiles. As a result of these changes, the passing score has increased over time as candidates exhibit greater mastery of the fundamental, relevant knowledge that the ABNS believes is required for the safe and effective practice of neurosurgery.

\section{Future}

The ABNS continuously seeks to improve in-training assessments, so that passing reflects a mastery of the relevant core curriculum. To this end, the ABNS is piloting a neuroanatomy examination that includes core neurosurgical anatomy and follows a mastery test design. Future plans include releasing question stems to make transparent what the ABNS deems the critical knowledge base for the performance of neurosurgery and to encourage candidates to focus self-study on that knowledge base. The primary examination will continue to incorporate a significant percentage of new questions in order to keep up with the evolution of neurosurgical knowledge.

\section{Pathway to Oral Examination}

Board certification is a voluntary process for neurosurgeons. Candidates must submit a completed application and supporting documents, which are reviewed by the ABNS directors (Table 1).

\section{Case Logs}

Candidates are required to submit a log of consecutive surgical cases performed as the attending surgeon of record so that the safety and scope of a candidate's realworld practice can be assessed. All cases must have been performed consecutively over a period of 18 months or less and include 3 months of clinical follow-up. Cases performed during a fellowship do not count toward the requirement. A written case log was first required beginning with June 1989 residency graduates. Initially, this case log was a text-based submission of a list that described the features of each case. However, the ABNS directors recognized that more information about the submitted cases was needed to properly evaluate a candidate's surgical indications and outcomes, most notably including representative pre- and postoperative imaging studies. In addition, ABNS directors decided that the oral examination would better reflect a candidate's reasoning and skill level if the submitted cases were evaluated as part of the examination process (see below). This led to the development and September 2018 implementation of the current ABNS Practice and Outcome of Surgical Therapies (POST) system, a web-based system that requires candidates to upload discrete clinical data elements and relevant images. Each case log is carefully reviewed by ABNS directors or selected subspecialty experts in the field. If issues are identified, the candidate's application may be deferred, and additional cases or a hearing may be requested for further discussion. Once a candidate's case submission is approved, a subset of the submitted cases is selected for the oral examination and slides are generated from the POST system. 


\section{Future}

Currently, the ABNS permits individuals to refer to themselves as "board eligible" from the time they complete training until they either become board certified or "time out" of the process. However, this allows individuals who never take intentional steps toward board certification to present themselves as board eligible and practice for several years without direct ABNS oversight. Moreover, the ABNS' current process does not facilitate any monitoring of practice from the time a candidate completes residency training until the submission of his or her case $\log$, which can take several years.

To better protect public safety during early neurosurgical practice, the ABNS is now initiating postresidency precertification monitoring for candidates who complete residency on or after June 30, 2021. Monitoring during the board-eligible time period will include submission of 10 consecutive surgical cases into the ABNS POST system for review within 6 months of training, as well as participation in the $\mathrm{CC}$ activities required of ABNS-certified neurosurgeons (see below, referred to as "tracking toward certification" for board-eligible candidates). Neurosurgeons who choose not to pursue these activities will not be board eligible, and thus will be distinguished from those who are board eligible and taking the appropriate steps to become certified.

\section{Oral Examination}

The format and structure of the ABNS oral examination has evolved significantly in recent years. The current structure of the oral examination now consists of three 45-minute sessions during which the candidates discuss five cases in each session. The candidate is examined by two examiners in each session so that after the examination, the candidate will have been examined by six different examiners. In each session, one examiner is a lead examiner who is a director, former director, or experienced ABNS examiner. The other examiner is typically a guest examiner. The two examiners grade each candidate independently of one another. The guest examiners list is created through a structured nomination and approval process supervised by the ABNS Executive Committee. Currently, the list includes most residency program directors and neurosurgery chairs from ACGME-accredited program-hosting departments. Other guest examiners may be peer nominated and selected to represent the diversity of the specialty, including such characteristics as subspecialty expertise, academic or hospital-based practice, or geographic considerations. Guest examiners are asked to submit written and oral examination questions and may be asked to review ABNS POST case logs. The ABNS board of directors evaluates guest examiners, and examiner performance is subjected to objective metrics, including rigorous statistical analysis of oral examination grades to ensure fair grading across the entire examination. Based on guest examiner performance metrics and participation in other ABNS activities, such as question writing, some guest examiners are selected by the ABNS directors to serve as an ABNS examiner and may serve as a lead examiner during the oral examination. Examinees are also surveyed for feedback about the examination process in an effort to continuously improve the experience for candidates.

In the past, candidates were examined using cases brought by the directors and guest examiners. In order to improve consistency, the process has evolved to the use of standardized questions for two of the three sessions. The three sessions focus on 1) general neurosurgery, 2) the candidate's identified area of focused practice (subspecialty), and 3) the candidate's own cases. General neurosurgery covers the broad range of conditions that neurosurgeons may see in practice or while on-call. The focused practice session allows the candidate to focus on the area that is a core component of his or her actual practice. A neurosurgeon may also choose to have a second session in general neurosurgery, rather than a subspecialty examination, if it best describes his or her practice. For the session focused on a candidate's own cases, the cases are selected from among those submitted as part of the candidate's case log.

Examiners are given guidelines on how to score candidate responses. Scores are then subjected to statistical analysis that accounts for examiner severity and consistency and the difficulty of the standard question. The oral examination undergoes rigorous psychometric testing similar to that done for the primary examination. If the candidate fails, he or she remains board eligible and may retake the examination up to twice more, subject to certain time limits. For the second attempt, candidates may elect to use their original case log for the session focused on their own cases or submit 75 new consecutive cases. A candidate who fails twice can no longer elect to use his or her initial case log submission for the third attempt and must submit 75 new cases (unless he or she had already done so prior to the second attempt). Candidates who fail the oral examination three times or fail to complete the entire process within 7 years after finishing training will time out of the process. If they time out, individuals must commence the entire process anew in order to become certified, beginning with taking and passing the primary (written) examination. Once an individual has timed out, he or she is no longer considered to be board eligible, even after recommencing the process, until the oral examination has been successfully passed.

Over the last 6 years, the oral examination has changed from a multiday to a single day examination schedule that takes place on one weekend day. In addition, the ABNS has increased the number of candidates examined on each examination day. In the fall of 2018, the ABNS examined 154 candidates, the largest number of candidates tested at one time in the history of the board. Going forward, the number of candidates examined per year will be tailored to more closely meet the demands of the field. Just over 200 residents graduate from ACGME-approved neurosurgery programs each year.

\section{Future}

As the candidate backlog for oral examinations has now been eliminated, the ABNS may consider further changes. Technological advances may also allow further evolution of the examination process, such as the possible 
TABLE 2. CC: four steps

\begin{tabular}{lc}
\hline \multicolumn{1}{c}{ Step } & Note \\
\hline $\begin{array}{l}\text { 1. Professionalism \& } \\
\text { professional standing }\end{array}$ & $\begin{array}{c}\text { Attestation of hospital privileges, } \\
\text { meaningful participation in quality } \\
\text { improvement \&/or patient safety } \\
\text { from chief medical officer, etc. }\end{array}$ \\
\hline $\begin{array}{l}\text { 2. Lifelong learning \& } \\
\text { self-assessment }\end{array}$ & $\begin{array}{c}\text { 20 AMA PRA Category 1 credits in } \\
\text { neurological surgery annually }\end{array}$ \\
\hline $\begin{array}{l}\text { 3. Assessment of knowledge, } \\
\text { judgment, \& skills }\end{array}$ & $\begin{array}{l}\text { Online adaptive learning tool } \\
\text { 4. Improvement in medical } \\
\text { practice }\end{array}$ \\
$\begin{array}{l}\text { Quarterly case review, e.g., morbid- } \\
\text { ity \& mortality conference, etc., } \\
\text { evaluation of personal outcomes \& } \\
\text { complications }\end{array}$ \\
\hline
\end{tabular}

PRA = Physician's Recognition Award.

implementation of virtual oral examinations when deemed appropriate. Case selection from the POST system may be increasingly based on analytics and benchmarks from the progressively growing practice-information repository.

\section{Recognition of Focused Practice}

One relatively recent development is that the ABNS now offers, in addition to its certificate in general neurosurgery, an additional credential in three subspecialty areas, several in collaboration with other ABMS member boards: pediatric neurosurgery, neurocritical care, and central nervous system endovascular surgery. Although the requirements are somewhat different for each of these subspecialty areas, candidates who wish to receive additional credentials in one or more of these areas generally must 1) successfully complete an accredited fellowship in their area of focused practice (or in some cases demonstrate practice experience that reflects an equivalent level of training), 2) successfully pass an online 100-question proctored examination in their area of focused practice (in addition to the ABNS general primary examination), 3) demonstrate through their case submission that a significant portion of their practice is devoted to their applicable area of focused practice, 4) select their applicable area of focused practice for the subspecialty portion of the ABNS oral examination, and 5) participate in annual focused CC. For pediatrics, the ABNS and the American Board of Pediatric Neurological Surgery (ABPNS) issue the additional credential for those neurosurgeons who qualify jointly. The ABNS works closely with the SNS Committee on Advanced Subspecialty Training (CAST) to determine criteria for the quality of neurosurgical subspecialty fellowship training.

\section{Future}

As neurosurgeons seek further training and expertise in subspecialty areas to advance the field, the ABNS may continue to work with other specialty boards to create new pathways for focused practice recognition in order to accommodate the continual evolution of the scope of neurosurgical practice over time.

\section{Continuous Certification}

The concept of lifelong learning is one of the traditional tenets of professionalism. Historically, lifelong learning in North American medicine has centered on continuing medical education (CME), including participation in medical meetings, practical courses, and other educational activities. In the 1990s, the ABMS formalized the concept of Maintenance of Certification (MOC) and required all medical specialty boards to compel their diplomates to regularly demonstrate current knowledge. Neurosurgery was the last specialty to adopt this process in 1998, and the ABNS implemented a 10 -year MOC process culminating in a written examination. Diplomates who successfully completed the process were issued renewal certificates at the end of each 10-year period. Since its inception, some diplomates complained that the process was burdensome and not sufficiently relevant to clinical practice. In response, the ABNS engaged with its diplomates through surveys and public forums over the past several years to find ways to improve the process. As a result, the ABNS modified the program to better reflect the needs of the diplomates and the public, recently introducing a new CC process focused entirely on clinically relevant knowledge updates, professionalism, and practice improvement.

The CC process uses an annual online adaptive learning tool, requires diplomates to participate in evaluating complications and improving their own clinical outcomes, verifies neurosurgery CME credits, and incorporates an online attestation of good standing and unencumbered medical license from an independent observer, such as the hospital's chief medical officer (Table 2).

The adaptive learning tool, in particular, is aimed at educating diplomates on information and new developments relevant to contemporary practice in a flexible environment, through an iterative process. Like the training and initial certification examinations discussed above, the adaptive learning tool prioritizes knowledge acquisition and demonstration of competency without the risk of "failing" a high-stakes examination. The ABNS defines the requirements for $\mathrm{CC}$ in neurological surgery, develops and administers the adaptive learning tool, and tracks diplomates' compliance with the other program requirements. These focused, annual CC requirements replace the previous 10-year ABNS MOC cycle in response to new ABMS requirements, as well as to the feedback and perception that the 10-year time period was too lengthy to ensure that diplomates remain current in a rapidly changing healthcare environment. ${ }^{5}$ Although the ABNS still issues a 10year time-limited certificate, the review process for compliance is annual. Diplomates with an additional credential in pediatric neurosurgery, neurocritical care, or central nervous system endovascular surgery are required to fulfill additional $\mathrm{CC}$ requirements to maintain this credential. Figure 2 depicts the overall pathway from residency to CC.

\section{Future}

The ABNS anticipates further evolution of its adaptive learning tool and related modules as an efficient and useful solution for diplomates. As needs are identified, this tool can be readily modified and expanded to implement evi- 


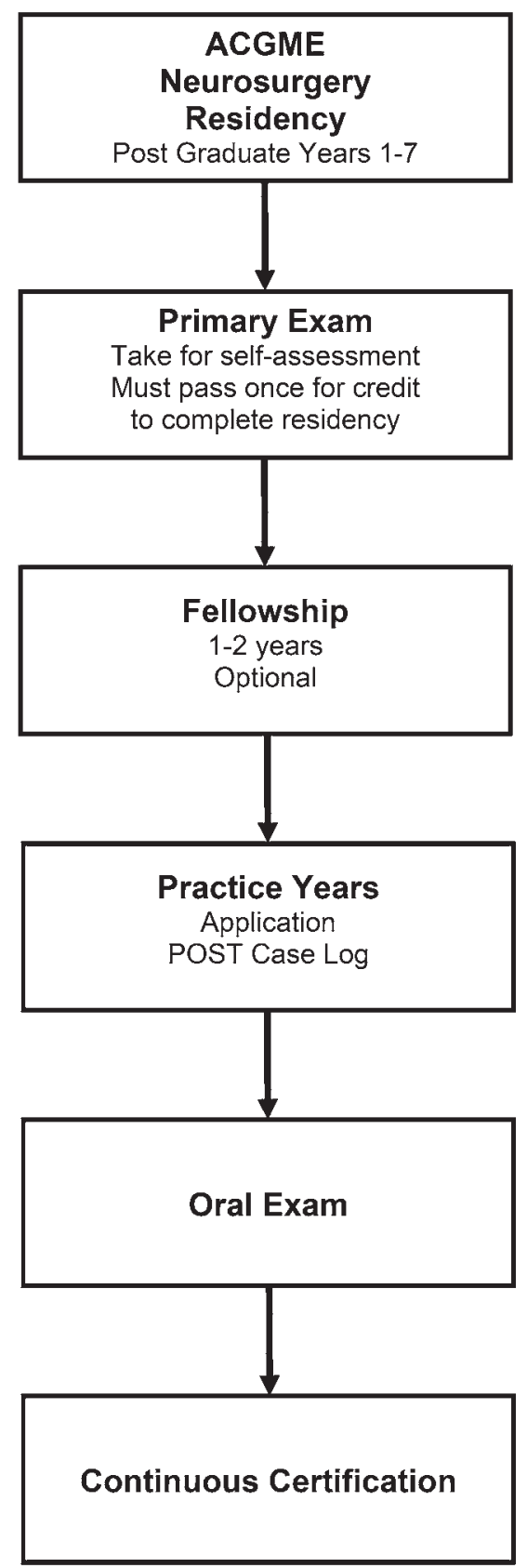

FIG. 2. Pathway from residency to CC.

dence-based learning in areas that will further the practice of neurosurgery, including areas such as coding, published evidence-based guidelines, and seminal high-impact clinical studies. Approximately $20 \%$ of learning tool content is changed each year to reflect the latest high-quality information available and to allow the ABNS to monitor learning over time and meet ABMS requirements for $\mathrm{CC}$.

\section{Conclusions}

The ABNS mission is to elevate standards for the practice of neurological surgery, in recognition of the need for detailed training and special qualifications for neurosurgeons and for self-regulation of quality and safety in the field. The ABNS is an activist board that continues to rapidly evolve and improve its activities to better serve the field of neurological surgery and the cause of public health.

\section{Acknowledgments}

We acknowledge K. Orrico, JD; J. G. Schneider, JD; and A. Dall-Knox.

\section{References}

1. Flexner A. Medical education in the United States and Canada. From the Carnegie Foundation for the Advancement of Teaching, Bulletin Number Four, 1910. Bull World Health Organ. 2002;80(7):594-602.

2. Starr P. The Social Transformation of American Medicine: The Rise of a Sovereign Profession and the Making of a Vast Industry. Basic Books; 1982.

3. Nora LM, McGreal SF, Nugent SG. Board certification: going back to the future. Ophthalmology. 2016;123(9 Suppl): S55-S60.

4. Bucy PC, Clark WK. The American Board of Neurological Surgery. A historical summary. Surg Neurol. 1977;7(5): 304-311.

5. Guiberteau MJ, Becker GJ. Counterpoint: maintenance of certification: focus on physician concerns. J Am Coll Radiol. 2015;12(5):434-437.

\section{Disclosures}

Dr. Cockcroft is the treasurer of the ABNS. Dr. Huang has ownership of Longeviti. Dr. Knightly is the chairman of the board of directors of NeuroPoint Alliance.

\section{Author Contributions}

Conception and design: Wang, Boop, Kondziolka, Resnick, Kalkanis, Selden, Heilman, Valadka, Cockroft, Wilson, Camarata, Knightly, Levy, Lonser, Meyer, Liau. Acquisition of data: Wang, Boop, Kondziolka, Resnick, Kalkanis, Koehnen, Valadka. Analysis and interpretation of data: Wang, Boop, Kondziolka, Resnick, Kalkanis, Valadka. Drafting the article: Wang, Boop, Kondziolka, Resnick, Kalkanis, Valadka. Critically revising the article: Wang, Kondziolka, Koehnen, Selden, Heilman, Cockroft, Wilson, Ellenbogen, Asher, Connolly, Meyer, Liau. Reviewed submitted version of manuscript: Wang, Boop, Kondziolka, Resnick, Kalkanis, Koehnen, Selden, Heilman, Valadka, Cockroft, Ellenbogen, Asher, Byrne, Camarata, Huang, Knightly, Levy, Lonser, Connolly, Meyer, Liau. Approved the final version of the manuscript on behalf of all authors: Wang. Administrative/ technical/material support: Koehnen.

\section{Correspondence}

Marjorie C. Wang: Medical College of Wisconsin, Milwaukee, WI.mwang@mcw.edu. 